\title{
Musicando: inserção social e cultural pela música
}

Recebido em 29.04.2015. Aprovado em 05.05. 2015

Avaliado pelo sistema double blind review

\author{
Maria de Fátima Medeiros Camargo Tofetti \\ fatimamedeiros@com4.com.br \\ EE Professor Alberto Ferriani - Ribeirão Preto - SP - Brasil.
}

\section{Resumo}

Flautas, alunos e professores compõem um cenário onde a atividade musical favorece o desenvolvimento integral do ser humano.

O objetivo geral do Projeto Musicando é realizar aulas de flauta doce para os alunos da EE Professor Alberto Ferriani, visando reduzir o índice de evasão escolar, além de promover o desenvolvimento das habilidades infantis através da educação musical. Tem como objetivo também incrementar, com estas atividades, a formação e a qualidade de vida dos alunos, tudo isso realizado em atividades grupais, visando a melhoria dos processos de ensino-aprendizagem.

Os resultados dessa formação musical vão além do aprendizado musical estão presentes também na melhoria do desempenho dos alunos nas escolas. O exercício da música desenvolve a capacidade de concentração tendo implicações no desempenho em sala de aula.

O Projeto Musicando visa também ser uma proposta de ensino para formar jovens à responsabilidade, à cidadania e ao empreendedorismo:

Responsabilidade, porque para freqüentar o projeto o aluno tem que ter presença nas aulas regulares;

Cidadania, pois independente das diversas expressões, etnias, classes sociais, idades e credos - 0 que importa no ambiente da música é o ser humano e seu sentido artístico. Portanto, a arte como linguagem universal e expressão do espírito humano e,

Empreendedorismo, pois o projeto visa também manter o jovem crescendo, fazendo arte, primeiro para ele mesmo, depois para sua família e depois, para o mundo, incentivando para que se torne um agente transformador e empreendedor de sua própria vida.

Fazendo isto vamos de encontro aos anseios dos pais quando, no início do ano, pediram à escola: "O que mais a escola tem para oferecer aos nossos filhos? Queremos alguma coisa diferente, que possa servir realmente para ele no futuro".

Anseios de uma comunidade carente, que vê na escola, no estudo de seus filhos uma esperança de dias melhores.

Palavras-chaves: Educação. Aprendizado Musical. Plano de empreendimento. Evasão escolar. 


\section{Musicando}

\section{Contexto da escola}

"A organização só existe quando há pessoas capazes de se comunicarem entre si, dispostas a contribuir com ações, a fim de cumprir um papel comum."

Este é o retrato da EE Professor Alberto Ferriani, localizada no município de Ribeirão Preto, escola da qual sou gestora. Vejo que em minha escola existe esta organização, tendo como valores a cooperação, a preocupação com o outro, o envolvimento nos problemas tentando resolvê-los da melhor forma possível, a preocupação com as diferenças.

\begin{tabular}{|c|c|c|}
\hline Nome: & \multicolumn{2}{|c|}{ E.E. PROFESSOR ALBERTO FERRIANI } \\
\hline $\begin{array}{lll}\text { Identificação } & \text { da } & \text { Entidade }\end{array}$ & \multicolumn{2}{|c|}{ Governo do Estado de São Paulo } \\
\hline Mantenedora: & \multicolumn{2}{|c|}{ Secretaria de Estado da Educação } \\
\hline Diretoria de Ensino: & \multicolumn{2}{|c|}{ Ribeirão Preto } \\
\hline Turnos: & \multicolumn{2}{|l|}{ Diurno } \\
\hline Cursos: & \multicolumn{2}{|c|}{ Ensino Fundamental - Ciclo I - Anos Iniciais } \\
\hline \multirow{2}{*}{ Períodos: } & Manhã: & 07h00min as $11 \mathrm{~h} 30 \mathrm{~min}$ \\
\hline & Tarde: & $13 \mathrm{~h} 00 \mathrm{~min}$ as $17 \mathrm{~h} 30 \mathrm{~min}$ \\
\hline \multirow[t]{2}{*}{ Séries: } & \multicolumn{2}{|c|}{$\begin{array}{l}\text { Manhã: } 1^{\circ} \mathrm{A}, 1^{\circ} \mathrm{B}, 2^{\circ} \mathrm{A}, 2^{\circ} \mathrm{B}, 3^{\circ} \mathrm{A}, 3^{\circ} \mathrm{B}, 4^{\circ} \mathrm{A}, 4^{\circ} \mathrm{B}, 5^{\circ} \mathrm{A}, 5^{\circ} \mathrm{B} \text { e Sala de Recursos } \mathrm{DI} \text { (Deficiente } \\
\text { Intelectual) }\end{array}$} \\
\hline & \multicolumn{2}{|c|}{ Tarde: $1^{\circ} \mathrm{C}, 1^{\circ} \mathrm{D}, 2^{\circ} \mathrm{C}, 2^{\circ} \mathrm{D}, 3^{\circ} \mathrm{C}, 4^{\circ} \mathrm{C}$ e $5^{\circ} \mathrm{C}$} \\
\hline Equipe de gestão & \multicolumn{2}{|c|}{$\begin{array}{l}\text { Diretor: Maria de Fátima Medeiros Camargo Tofetti } \\
\text { Vice-diretor: Aparecida das Graças Leão da Costa } \\
\text { Professor Coordenador: Regina Ângela Depiro Stocco Jorge }\end{array}$} \\
\hline
\end{tabular}

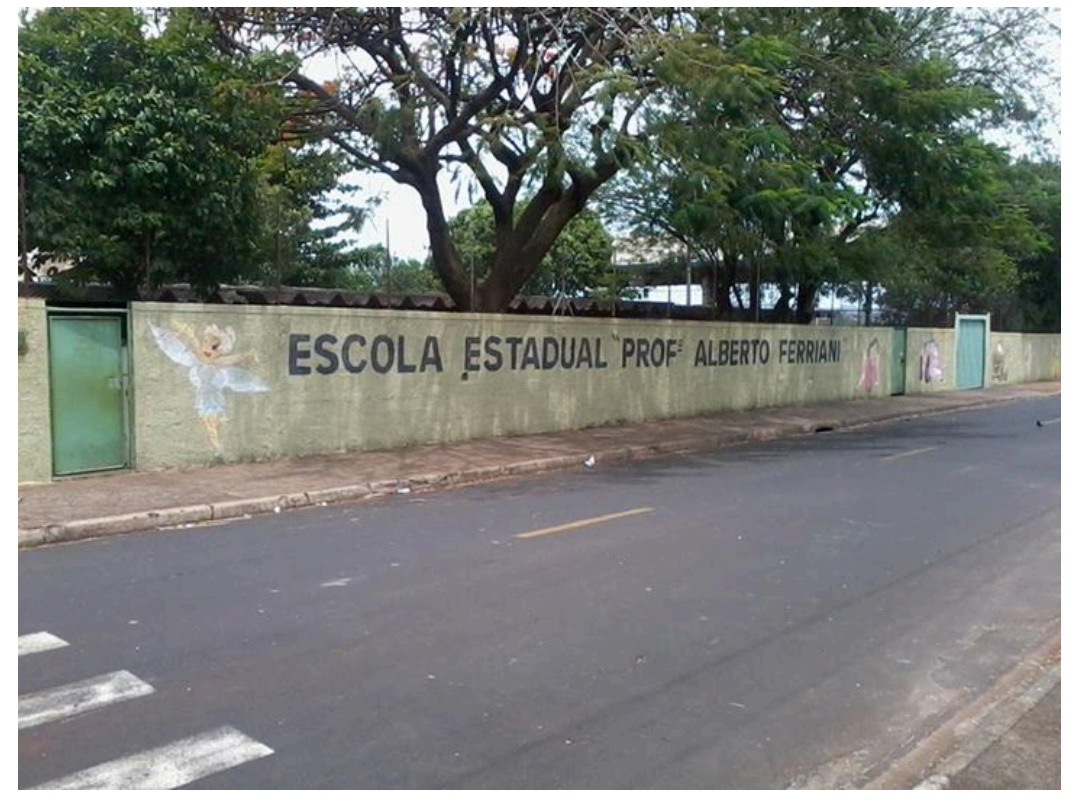


A EE Professor Alberto Ferriani foi fundada em 1983, atendendo em seu início 1. e 2. Graus (denominação da época), mais tarde passando a atender o ensino atual, Ensino Fundamental, com crianças de 6 à 10 anos Anos Iniciais - 1. ao 5. Ano. Possui hoje 398 alunos, sendo 224 no período da manhã e 174 no período da tarde, assim distribuídos:

\begin{tabular}{|c|c|c|c|}
\hline \multicolumn{2}{|c|}{ MANHÃ } & \multicolumn{2}{|c|}{ TARDE } \\
\hline Classe & Alunos & Classe & Alunos \\
\hline $1 . \mathrm{A}$ & 16 & 1.C & 18 \\
\hline $1 . B$ & 17 & $1 . \mathrm{D}$ & 17 \\
\hline $2 . A$ & 24 & $2 . C$ & 26 \\
\hline $2 . B$ & 22 & $2 . D$ & 27 \\
\hline $3 . A$ & 23 & 3.C & 25 \\
\hline $3 . B$ & 22 & 4.C & 30 \\
\hline $4 . A$ & 25 & $5 . C$ & 31 \\
\hline $4 . B$ & 25 & & \\
\hline $5 . \mathrm{A}$ & 25 & & \\
\hline $5 . B$ & 25 & & \\
\hline TOTAL & 224 & TOTAL & 174 \\
\hline & TOTAL & 398 & \\
\hline
\end{tabular}

Possui ainda uma Sala de Recursos - Deficiência Intelectual, atendendo 12 alunos, divididos em 03 turmas, com 02 aulas diárias, atendidos no período da manhã, contados somente no período da tarde, onde freqüentam também o ensino regular.

Apresenta em seu quadro docente 18 professores, sendo 09 efetivos e 09 pertencentes à Categoria $F$, professores que foram admitidos pela Lei 500/74, consideráveis estáveis após a Lei 1010/2007. Além destes, temos também os professores auxiliares, num total de 12 docentes. Entre eles existe um clima de participação, colaboração, cooperação muito grande. As pessoas que aqui trabalham estão sempre dispostas a trabalhar pelo bem comum. Com certeza isso se dá também pela maioria estar aqui a mais de 15 anos, 0 que viabiliza este clima de parceria constante entre todos. Os novos, quando chegam, são recebidos muito bem, por todos.

A comunidade escolar é composta, em sua maioria, de pessoas de classe economicamente baixa. 0 bairro da escola é um bairro de casas populares e, no entorno escolar existem 02 favelas. Segundo um questionário diagnóstico feito no início do ano de $2014,90 \%$ das crianças do bairro e da favela são nossos alunos. Existe uma carência sócio-econômica-afetiva grande, que procuramos sanar através de relacionamento intenso com as famílias e também através de nossos projetos.

O ambiente em nossa escola é um ambiente acolhedor, onde as pessoas se comunicam entre si, sempre dispostas a contribuir com ações para a melhoria do ambiente escolar, trazendo com isso uma melhora no ensino-aprendizagem. $O$ aluno se sente acolhido, respeitado, tendo como conseqüência um relacionamento idêntico com trabalho e dispostos a ajudar seus parceiros.

Trabalhamos muito com projetos, pois entendemos que por meio deles incorporamos ainda mais o "fazer" do aluno. Participamos dos seguintes projetos da Secretaria da Educação: Prevenção também se ensina; Ler e Escrever (Língua Portuguesa); EMAI (Matemática); Cultura é Currículo (Arte); Professor Auxiliar. Além destes também desenvolvemos projetos que atendem as especificidades da escola e também de sua comunidade, 0 que é o Nosso Diferencial: Prevenção da Dengue; Projeto Alimentação; Projeto Meio Ambiente; Projeto Reciclagem; Projeto Descobrindo o prazer da leitura; Projeto Aluno Destaque; Projeto Jogos e Brincadeiras (Recreio Dirigido). Além destes projetos também são destaques as comemorações das datas cívicas e 
comemorativas - 7 de setembro, Tiradentes, Dias das Mães e dos Pais - aos poucos transformado em Dia da Família, bem como o canto dos hinos pátrios e do município, semanalmente. A escola também aderiu ao Programa Mais Educação, programa do Governo Federal.

É uma escola que, se comparada às outras, não apresenta problemas mais graves. Há 04 anos atinge as metas propostas. Os alunos e também seus pais, dão valor e importância ao estudo.

Um fato que me incomoda é o índice de evasão, pequeno, se comparado também às outras escolas. Mas não podemos ignorar este fato. A escola está aí para atender os alunos, procurando tornar seu espaço, seu ensino, seu relacionamento, dinâmico, interessante e que atinja os objetivos propostos em seu Projeto Político Pedagógico.

\section{Missão}

Organização efetiva de uma prática docente que considere o aluno como centro motivador do processo de conhecimento, transformando-o e tornando-o capaz de refletir e agir em seu meio social.

\section{Visão}

Ser uma escola que seja reconhecida pelo seu empenho em fazer de seu educando parte integrante de seu processo de ensino, valorizando seus aprendizados anteriores e dando a ele condições de que seu aprendizado de hoje sirva de alicerce para sua vida futura, seja por meio da continuidade de seus estudos, seja por meio do mercado de trabalho.

\section{Identificação do problema ou da oportunidade}

\section{Problema: evasão}

Pequena, se comparado às outras escolas. Mas, como relatei anteriormente não podemos ignorar este fato. Sabemos que a evasão, por menor que seja, atrapalha o desenvolvimento do aluno. É função da escola estar atenta aos alunos faltosos, garantir a eles o direito à compensação de ausências, mediante solicitação feita por seus pais ou responsáveis. Mesmo assim, assegurando todos os direitos dados à eles, ainda temos um número de alunos que ficam reprovados por ausência.

No início deste ano de 2014 fizemos um questionário diagnóstico que nos forneceu a informação que, estes alunos que ficaram reprovados, retornaram à escola. Não "desapareceram" da escola, nem tampouco se importaram com a reprovação. A maioria lamentou apenas por ter perdido o benefício da Bolsa Família, benefício este repassado pelo Governo Federal, cerca de $25 \%$. Com este questionário também levantamos outros dados: $30 \%$ das famílias sobrevivem com dois salários mínimos, a maioria dos pais não tem emprego fixo, e muitos levam seus filhos para trabalharem com eles, daí a evasão escolar.

Com estes dados na mão, começamos o nosso trabalho. Primeiro de conscientização da família da importância da escola, do estudo de seus filhos, da valorização do saber. Logo no início do trabalho ficamos intrigados com a fala de alguns pais: "O que mais a escola tem para oferecer aos nossos filhos? Queremos alguma coisa diferente, que possa servir realmente para ele no futuro".

Nesse momento começamos a nos questionar. O que poderia ser essa "coisa diferente?" Voltamos a conversar com eles e descobrimos que "essa coisa diferente" era algo relacionado ao seu futuro, alguma coisa que lhe trouxesse um maior interesse em participar das atividades escolares e que também servisse para um futuro melhor.

Foi aí que me veio a idéia de trazer a música para dentro da escola. Poderia aliar o prazer do fazer musical auxiliando no ensino aprendizagem, e também, quem sabe, auxiliar nossos alunos em seu futuro, financeiramente falando. Uma coisa nova, nunca vista antes pelos alunos. A música tem um papel primordial como forma de lazer e na socialização das pessoas, pois ela cria e reforça laços sociais e vínculos afetivos. Além disso, a música exerce um relevante papel na formação cultural das pessoas, por meio do repasse de idéias, informações e conceitos, servindo para o aprimoramento do aprendizado. Além disso, acreditamos também que com a inserção da música no dia-a-dia da escola e no cotidiano de nossa comunidade 
poderemos ocupar de forma prazerosa o tempo ocioso de nossas crianças, tirando-as da rua, que é onde ficam no período contrário aos seus estudos, contribuindo assim para a sua formação integral.

\section{Caracterização do produto/serviço e/ou processo}

\section{"O que mais a escola tem para oferecer aos nossos filhos? Queremos alguma coisa diferente, que possa servir realmente para ele no futuro".}

Foi partindo desse questionamento feito por alguns pais de nossos alunos que surgiu a idéia desse projeto de música, aliada à minha formação primeira.

O Projeto Musicando consiste em aulas de musicalização, com ênfase no instrumento flauta doce. Sabemos que a música é uma atividade essencial para o desenvolvimento das crianças, pois considera que os elementos de ritmo, melodia e harmonia integram a pessoa em um mundo sonoro capaz de proporcionar, por meio do fazer musical, seu desenvolvimento global.

As aulas serão desenvolvidas por professor especialista, com formação musical e, principalmente, com conhecimentos em musicalização infantil. Isso é de fundamental importância uma vez que é através dessa musicalização que a criança desenvolve os aspectos cognitivos, perceptivos, psicoemocionais, corporais, sociais e de criatividade.

Ainda pensando no desejo dos pais, que pensam e almejam um futuro melhor para seus filhos, procuramos trazer uma coisa nova para eles. A aula de música vivenciada hoje por eles poderá ser no futuro, uma forma de melhorar a vida financeira da família, pois sabemos que não existe, no entorno escolar um curso com estas características.

\section{Divulgação do Projeto Musicando}

Levando em consideração que "a propaganda é a alma do negócio" a melhor forma de se fazer isso é mostrando à comunidade escolar o nosso projeto. Um bom início é fazer uma recepção aos alunos e pais. 0 professor do curso fará uma apresentação informal no portão de entrada dos alunos, em sua chegada a escola, logo às 7 horas da manhã e também na entrada do período da tarde, às 13 horas. Em seguida, os pais serão convidados a entrar na escola onde serão "apresentados" ao projeto, recebendo um folder que conterá as informações necessárias para efetivação da matrícula de seu filho no projeto.

\section{Desenvolvimento do Projeto}

As aulas serão desenvolvidas no período contrário às aulas dos alunos. As turmas serão organizadas por faixa etária, com duas aulas semanais, tendo a duração de 50 minutos cada.

Inicialmente a matrícula será facultativa, pois entendemos que o aluno deve ter prazer e principalmente vontade em participar. Todos os alunos poderão fazer parte do projeto, tendo como única exigência sua freqüência regular no curso normal.

A exigência da freqüência é a oportunidade que temos em diminuir a pequena, mas importante evasão escolar que temos. Importante, pois sabemos o quanto a falta da presença escolar atrapalha no desenvolvimento do ensino aprendizagem. Como relatado anteriormente alguns pais acabam tirando seus filhos da escola para os ajudarem no trabalho do dia-a-dia, para reforçarem o orçamento familiar. Queremos, com este projeto, acabar com isso. Os alunos terão oportunidade, no futuro, de continuarem ajudando seus pais, podendo, quem sabe, serem os futuros professores de novos projetos como este.

Através de pesquisas a equipe gestora conseguiu encontrar outros projetos com propostas semelhantes e que serviram de inspiração para a construção do Projeto Musicando. Dentre estes projetos podemos citar:

http://www.recantomaestro.com.br/_.../0be334b4f56c7fd749c190c90c919100... 


\section{Musicando}

Posteriormente temos o desejo que todos os alunos da escola participem do projeto. Além de ocupar parte do tempo ocioso das crianças o "estar" na escola durante todo o dia é importante para que não fiquem na rua. É função também da escola fazer parte da formação integral da criança.

\section{Estratégia de implementação}

\section{Análise SWOT}

\begin{tabular}{|l|l|}
\hline Forças & Fraquezas \\
\hline $\begin{array}{l}\text { - Equipe docente coesa, comprometida, há muitos } \\
\text { anos na mesma escola } \\
\text { - Comprometimento da equipe gestora, auxiliando na } \\
\text { parte pedagógica, sempre que necessário }\end{array}$ & $\begin{array}{l}\text { - Evasão escolar } \\
\text { - Alunos que apresentam dificuldades no ensino } \\
\text { aprendizagem devido às constantes ausências } \\
\text { - Alunos reprovados em virtude de ausên- cias não } \\
\text { compensadas }\end{array}$ \\
\hline Oportunidades & Ameaças \\
\hline $\begin{array}{l}\text { - Pais comprometidos com o estudo dos filhos, mesmo } \\
\text { ainda sendo a minoria, porém uma minoria muito } \\
\text { interessada } \\
\text { - Pais que querem um futuro melhor para seus filhos e } \\
\text { vêem, no estudo, talvez uma chance de isso acontecer }\end{array}$ & $\begin{array}{l}\text { - Famílias de classe econômica baixa, portanto pais } \\
\text { trabalhadores que na maioria não comparecem à escola } \\
\text { por este motivo } \\
\text { - Pais quento da renda familiar } \\
\text { aumentaram da escola para ajudarem no }\end{array}$ \\
\hline
\end{tabular}

Objetivos, metas e estratégias

\begin{tabular}{|c|c|c|}
\hline \multicolumn{3}{|c|}{ Definição das Estratégias } \\
\hline Objetivos & Metas & Estratégias \\
\hline Reduzir a taxa de evasão & $\begin{array}{l}\text { Diminuir em } 90 \% \text { ao longo da } \\
\text { realização do Projeto (24 meses) }\end{array}$ & $\begin{array}{l}\text { - Identificar os problemas } \\
\text { enfrentados pelos alunos } \\
\text { - Estimular o interesse dos alunos } \\
\text { através de ativida-des } \\
\text { extracurriculares }\end{array}$ \\
\hline $\begin{array}{l}\text { Incentivar o trabalho em grupo para } \\
\text { melhorar os processos de ensino- } \\
\text { aprendizagem. }\end{array}$ & $\begin{array}{l}\text { Através da divulgação dos } \\
\text { trabalhos realizados aumen tar em } \\
50 \% \text { o número de matrículas para o } \\
\text { 20. ano do projeto }\end{array}$ & $\begin{array}{l}\text { - Avaliação ao final do 10. semestre } \\
\text { do projetos atra-vés de análise de } \\
\text { registros e pesquisas de satisfação; }\end{array}$ \\
\hline $\begin{array}{l}\text { Incentivar o aluno para que se torne } \\
\text { um agente trans-formador e } \\
\text { empreendedor na fase adulta. }\end{array}$ & $\begin{array}{l}\text { Estimular em } 80 \% \text { a con-tinuidade } \\
\text { dos estudos mu-sicais, após } 24 \\
\text { meses de projeto }\end{array}$ & $\begin{array}{l}\text { - Presentear o aluno com } 0 \\
\text { instrumento flauta }\end{array}$ \\
\hline
\end{tabular}




\section{Plano de ação}

\begin{tabular}{|c|c|c|c|c|c|c|}
\hline 0 que? & Onde? & Quando? & Por quê? & Quem? & Como? & Quanto? \\
\hline $\begin{array}{l}\text { Realizar reunião } \\
\text { com } \\
\text { professores e } \\
\text { funcionários }\end{array}$ & $\begin{array}{l}\text { Sala de } \\
\text { Coordenação }\end{array}$ & $\begin{array}{l}\text { Durante o pla- } \\
\text { nejamento, no } \\
\text { início do ano } \\
\text { letivo de } 2015\end{array}$ & $\begin{array}{l}\text { Para exposição } \\
\text { do Projeto e } \\
\text { apresentação do } \\
\text { professor } \\
\text { especialista }\end{array}$ & $\begin{array}{l}\text { Equipe } \\
\text { Gestora: } \\
\text { Diretor,Vice- } \\
\text { Diretor e } \\
\text { Coordenador } \\
\text { Pedagógico }\end{array}$ & $\begin{array}{l}\text { Durante o encontro } \\
\text { expor como o } \\
\text { Projeto funcionará: } \\
\text { público alvo, } \\
\text { matrículas, horários } \\
\text { das aulas }\end{array}$ & - \\
\hline $\begin{array}{l}\text { Apresentação } \\
\text { Musical }\end{array}$ & $\begin{array}{l}\text { Portão de } \\
\text { entrada de } \\
\text { alunos }\end{array}$ & $\begin{array}{l}1^{\text {a }} \text { Semana } \\
\text { de Aula, início } \\
\text { do ano de } \\
2015\end{array}$ & $\begin{array}{l}\text { Para apresenta- } \\
\text { cão do Projeto } \\
\text { Musicando aos } \\
\text { pais e alunos, de } \\
\text { forma descon- } \\
\text { traída }\end{array}$ & $\begin{array}{l}\text { Professor Es- } \\
\text { pecialista que } \\
\text { ministrará o } \\
\text { curso }\end{array}$ & $\begin{array}{l}\text { De maneira } \\
\text { informal os pais } \\
\text { serão recebidos } \\
\text { com música, nesta } \\
\text { semana }\end{array}$ & - \\
\hline $\begin{array}{l}\text { Apresentação } \\
\text { do Projeto }\end{array}$ & $\begin{array}{l}\text { Pátio da Esco- } \\
\text { la }\end{array}$ & $\begin{array}{l}\text { Após a } \\
\text { Recep-ção } \\
\text { Musical } \\
\text { realizada em } \\
\text { sua chegada }\end{array}$ & $\begin{array}{l}\text { Para apresenta- } \\
\text { ção do Projeto } \\
\text { Musicando aos } \\
\text { pais e alunos, } \\
\text { agora de } \\
\text { maneira formal }\end{array}$ & $\begin{array}{l}\text { Equipe Gestora } \\
\text { e Professor } \\
\text { Especialista }\end{array}$ & $\begin{array}{l}\text { Serão distribuídos } \\
\text { folders de } \\
\text { apresenta-ção do } \\
\text { projeto, segui-do de } \\
\text { explanação do } \\
\text { projeto }\end{array}$ & $\begin{array}{l}\mathrm{R} \$ 150,00 \\
(500 \\
\text { folders })\end{array}$ \\
\hline $\begin{array}{l}\text { Matrículas para } \\
\text { o Projeto }\end{array}$ & $\begin{array}{l}\text { Secretaria da } \\
\text { Escola }\end{array}$ & $\begin{array}{l}1^{\text {a }} \text {. semana } \\
\text { de aula do } \\
\text { ano de } 2015\end{array}$ & $\begin{array}{l}\text { Para } \\
\text { organização das } \\
\text { turmas }\end{array}$ & $\begin{array}{l}\text { Professor Es- } \\
\text { pecialista }\end{array}$ & $\begin{array}{l}\text { Divisão das turmas, } \\
\text { por série/ano, de } \\
\text { acordo com a faixa } \\
\text { etária }\end{array}$ & - \\
\hline Início do Projeto & Salas de aula & $\begin{array}{l}2^{a} \text {. Semana } \\
\text { de aulas do } \\
\text { ano de } 2015\end{array}$ & $\begin{array}{l}\text { Para iniciar o } \\
\text { projeto }\end{array}$ & $\begin{array}{l}\text { Professor Es- } \\
\text { pecialista }\end{array}$ & $\begin{array}{l}\text { Iniciar as aulas de } \\
\text { musicalização }\end{array}$ & $\begin{array}{l}\mathrm{R} \$ 15,00 \\
\text { (valor da } \\
\text { hora aula) }\end{array}$ \\
\hline $\begin{array}{l}\text { Realizar reunião } \\
\text { do Professor } \\
\text { Especialista } \\
\text { com a Equipe } \\
\text { Gestora }\end{array}$ & $\begin{array}{l}\text { Sala de } \\
\text { Coordenação }\end{array}$ & $\begin{array}{l}\text { Ao final do } 1^{0} \text {. } \\
\text { Mês de aula }\end{array}$ & $\begin{array}{l}\text { Para analisar o } \\
\text { andamento do } \\
\text { Projeto }\end{array}$ & $\begin{array}{l}\text { Equipe Gestora } \\
\text { e Professor } \\
\text { Especialista }\end{array}$ & $\begin{array}{l}\text { Discutir o aproveita- } \\
\text { mento dos alunos, } \\
\text { presença às aulas } \\
\text { e interesse } \\
\text { demonstrado por } \\
\text { eles }\end{array}$ & - \\
\hline $\begin{array}{l}\text { Realizar reunião } \\
\text { de professores } \\
\text { com a Equipe } \\
\text { Gestora }\end{array}$ & $\begin{array}{l}\text { Sala de } \\
\text { Coordenação }\end{array}$ & $\begin{array}{l}1^{\circ} . \text { ATPC do } \\
\text { Mês de Março }\end{array}$ & $\begin{array}{l}\text { Para informar } \\
\text { aos professores } \\
\text { da escola o } \\
\text { anda-mento do } \\
\text { Projeto e } \\
\text { verificar pos- } \\
\text { síveis mudanças } \\
\text { no } \\
\text { comportamen- to } \\
\text { dos alunos }\end{array}$ & $\begin{array}{l}\text { Equipe Gestora } \\
\text { e Professores } \\
\text { da Escola }\end{array}$ & $\begin{array}{l}\text { Trazer gráficos da } \\
\text { presença e do } \\
\text { aproveitamento dos } \\
\text { alunos }\end{array}$ & - \\
\hline
\end{tabular}




\section{Indicadores para acompanhamento do projeto}

- Aprovação do Projeto

- Aprendizagem no Projeto: no início das aulas de musicalização não existem avaliações periódicas para se verificar o aprendizado dos alunos. Quando se inserir o instrumento flauta será feito avaliação contínua pelo professor, durante as aulas semanais e, após o primeiro mês de estudo poderá, a critério do professor, ser feita uma avaliação mensal para acompanhamento do progresso do aluno. Esta avaliação poderá ser feita a critério do professor porque, dependendo de alguns fatores como, número de alunos por turma, faixa etária, o professor consegue fazer a avaliação durante a própria aula, não precisando marcar uma avaliação mensal para se verificar a aprendizagem do aluno.

- Permanência dos alunos

- Freqüência dos alunos, no Projeto e nas aulas regulares

- Assiduidade dos professores

O acompanhamento do projeto deverá acontecer durante e após o término do projeto e deve contar com a participação do professor especialista e também dos professores do curso regular. É importante $o$ acompanhamento da equipe gestora e dos pais de alunos.

\section{Recursos necessários}

\begin{tabular}{|l|l|l|}
\hline \multicolumn{1}{|c|}{ O que vou precisar } & \multicolumn{1}{|c|}{ Descrição } & \multicolumn{1}{c|}{ Como obter } \\
\hline $\begin{array}{l}\text { Material didático para os alunos e } \\
\text { professores }\end{array}$ & $\begin{array}{l}\text { Folhas sulfites,folhas sulfi-tes } \\
\text { pautadas, lápis,borracha lápis de } \\
\text { cor, tinta guache, pincéis, papéis } \\
\text { diversos, cartucho colorido e } \\
\text { cartucho preto para impressora } \\
\text { multifuncional }\end{array}$ & $\begin{array}{l}\text { Verba prevista para mate-riais de } \\
\text { consumo,conforme edital }\end{array}$ \\
\hline Instrumentos Musicais & $\begin{array}{l}\text { Bandinha musical infantil, Flauta } \\
\text { doce, Teclado Musi cal, Estantes } \\
\text { para partituras }\end{array}$ & $\begin{array}{l}\text { Verba prevista como mate- rial } \\
\text { permanente, conforme edital }\end{array}$ \\
\hline Aparelhagem de som & $\begin{array}{l}\text { Microfone, Caixa de som } \\
\text { amplificada }\end{array}$ & $\begin{array}{l}\text { Verba prevista como material } \\
\text { permanente, conforme edital }\end{array}$ \\
\hline
\end{tabular}

\section{Marketing e Comunicação}

\section{"O que mais a escola tem para oferecer aos nossos filhos? Queremos alguma coisa diferente, que possa servir realmente para ele no futuro".}

Novamente me reporto a este questionamento feito por alguns pais de alunos. Não foi preciso fazer pesquisa para saber o que eles esperavam da escola. Este é realmente o papel do marketing: oferecer produtos que sejam atrativos para os clientes/usuários. 
Como descrito anteriormente nossa escola trabalha muito com projetos, pois entendemos que por meio deles incorporamos ainda mais o "fazer" do aluno. Assim a escola, através de atividades práticas, dinâmicas e lúdicas consegue oferecer um serviço de qualidade e diariamente aprimorar o relacionamento construído entre as partes: escola-cliente/usuário, atendendo principalmente o interesse de alunos e pais.

O projeto será divulgado para a comunidade escolar primeiramente:

- com uma recepção musical, informal, no portão da escola, durante a entrada dos alunos, feita pelo professor especialista que ministrará as aulas;

- em seguida serão convidados a participarem de uma palestra de apresentação do projeto, onde receberão um folder constando os objetivos do projeto e também o cronograma das aulas;

- todos os murais da escola conterão informação sobre o projeto;

- o projeto será divulgado também no site da escola.

Como o projeto se iniciará no 1.0 semestre haverá a Primeira Audição Musical durante as festividades de encerramento do 1. semestre letivo, em junho/2015, momento este onde poderão ser desfrutados momentos de prazer através da música, como também um momento para avaliação dos resultados do projeto, até então apresentados. 


\section{Musicando}

\section{Organização e Gerência do Empreendimento}

\section{Perfil e Experiência da Equipe Gestora}

\begin{tabular}{|c|c|c|c|}
\hline NOME & FUNÇÃO & $\begin{array}{l}\text { FORMAÇÃO E } \\
\text { EXPERIÊNCIA } \\
\end{array}$ & $\begin{array}{c}\text { PRINCIPAIS ATIVIDADES } \\
\text { (NO PROJETO) }\end{array}$ \\
\hline $\begin{array}{l}\text { Maria de Fátima } \\
\text { Medeiros Camar- } \\
\text { go Tofetti }\end{array}$ & Diretora Geral & $\begin{array}{l}\text { Formada em Educação } \\
\text { Artística com habilita - cão em } \\
\text { Música. Também pedagoga e } \\
\text { atualmente cursando MBA } \\
\text { Gestão Empreen- dedora em } \\
\text { Educação. Gestora efetiva na } \\
\text { SEE/SP desde 2002, nesta } \\
\text { escola desde dezembro de } \\
2012 \text {. }\end{array}$ & $\begin{array}{l}\text { Gestora responsável pela tomada } \\
\text { de preços, orçamentos e } \\
\text { prestação de contas das verbas } \\
\text { destinadas à escola, bem como } \\
\text { responsável pela parte } \\
\text { pedagógica do projeto, inclusive } \\
\text { pela contratação do professor } \\
\text { especialista. } \\
\text { Divulgação do projeto junto aos } \\
\text { alunos }\end{array}$ \\
\hline $\begin{array}{l}\text { Aparecida das Graças } \\
\text { Leão da Costa }\end{array}$ & Vice-Diretora & $\begin{array}{l}\text { Formada em Pedagogia, } \\
\text { afastada da sala de aula para } \\
\text { desempenhar esta função, } \\
\text { nesta escola, desde } 2006 \text {. }\end{array}$ & $\begin{array}{l}\text { Auxiliar a Diretora Geral na parte } \\
\text { pedagógica, elaborando os } \\
\text { horários das turmas do projeto. } \\
\text { Marcar as reuniões de divulgação } \\
\text { do projeto junto aos professores } \\
\text { e pais. }\end{array}$ \\
\hline $\begin{array}{l}\text { Regina Ângela Depiro } \\
\text { Stocco Jorge }\end{array}$ & $\begin{array}{l}\text { Coordenadora } \\
\text { Pedagógica }\end{array}$ & $\begin{array}{l}\text { Professora nesta escola, desde } \\
2008 \text { e coordenadora pedagó- } \\
\text { gica de todos os projetos } \\
\text { desenvolvidos pela Unidade } \\
\text { Escolar }\end{array}$ & $\begin{array}{l}\text { Fazer o controle do uso da sala } \\
\text { bem como acompanhar o } \\
\text { desenvolvimento dos alunos } \\
\text { atendidos. } \\
\text { Responsável pela análise do } \\
\text { andamento do projeto. }\end{array}$ \\
\hline
\end{tabular}

\section{Principais processos}

A tabela a seguir, mostra o perfil da equipe e os principais processos de trabalho necessários para a realização do empreendimento:

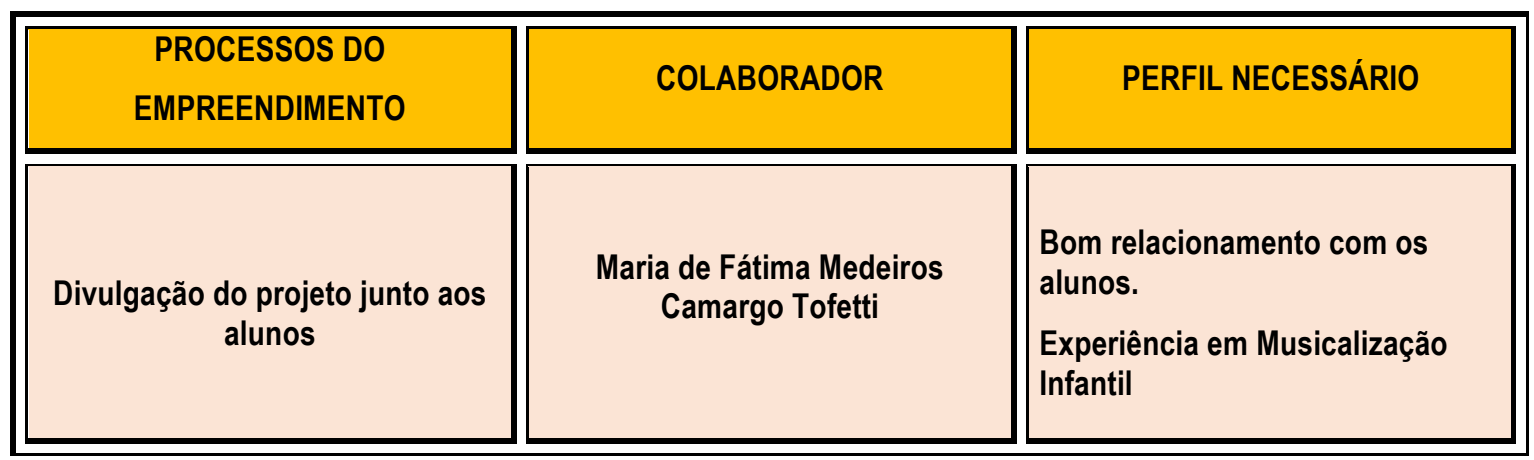




\begin{tabular}{|c|c|c|}
\hline $\begin{array}{c}\text { Divulgação junto aos professores } \\
\text { e pais de alunos. }\end{array}$ & $\begin{array}{c}\text { Aparecida das Graças Leão da } \\
\text { Costa }\end{array}$ & $\begin{array}{l}\text { Bom relacionamento e boa } \\
\text { comunicação verbal. } \\
\text { Reconhecimento da co- } \\
\text { munidade pelos trabalhos e } \\
\text { projetos que desenvolve na } \\
\text { Escola }\end{array}$ \\
\hline $\begin{array}{l}\text { Confeccionar materiais para as } \\
\text { reuniões de divulgação do } \\
\text { projeto, digitar os horários e } \\
\text { afixar nos murais. }\end{array}$ & $\begin{array}{l}\text { Patrícia Áurea Ribeiro Amaro e } \\
\text { Sérgio de Jesus do Carmo Júnior }\end{array}$ & $\begin{array}{l}\text { Gerente de Organização Escolar e } \\
\text { Agente de Organização Escolar, } \\
\text { respectivamente, com domínio } \\
\text { em computação gráfica }\end{array}$ \\
\hline $\begin{array}{l}\text { Coordenação e acompanhamento } \\
\text { da compra de equipamentos }\end{array}$ & $\begin{array}{l}\text { Maria de Fátima Medeiros } \\
\text { Camargo Tofetti }\end{array}$ & $\begin{array}{l}\text { Diretora da Escola } \\
\text {-especialização em Musicalização } \\
\text { Infantil, } \\
\text {-conhecimento prático e teórico } \\
\text { de música }\end{array}$ \\
\hline $\begin{array}{l}\text { Fazer acompanhamento do uso } \\
\text { das salas do projeto e também do } \\
\text { desenvolvimento dos alunos }\end{array}$ & $\begin{array}{c}\text { Regina Ângela Depiro Stocco } \\
\text { Jorge }\end{array}$ & $\begin{array}{l}\text { Coordenadora Pedagógi- } \\
\text { ca: } \\
\text { - com experiência em } \\
\text { acompanhamento de atividades } \\
\text { escolares } \\
\text { - experiência em confec- cão de } \\
\text { gráficos de acom- panhamento } \\
\text { escolar }\end{array}$ \\
\hline $\begin{array}{l}\text { Iniciar as atividades do Projeto } \\
\text { Musicando }\end{array}$ & Professor Especialista & $\begin{array}{l}\text { Experiência em Musicaliza- cão } \\
\text { Infantil e Flauta Doce }\end{array}$ \\
\hline
\end{tabular}

\section{Plano Financeiro} Investimento (despesa de capital)

\begin{tabular}{|l|c|c|}
\hline \multicolumn{1}{|c|}{ Item } & Ano1 & Ano2 \\
\hline \multicolumn{1}{|c|}{ Obras e infraestrutura } & $1.000,00$ & 0,00 \\
\hline Forração acústica da sala & $1.000,00$ & 0,00 \\
\hline \multicolumn{1}{|c|}{ Material permanente } & $17.750,00$ & $3.000,00$ \\
\hline Aparelhagem de Som & $3.000,00$ & 0,00 \\
\hline Teclado Musical & $5.500,00$ & 0,00 \\
\hline Bandinha Musical Infantil & $1.750,00$ & 0,00 \\
\hline Flauta Doce Germânica & $6.000,00$ & $3.000,00$ \\
\hline Estantes para Partituras & $1.500,00$ & 0,00 \\
\hline Total & $18.750,00$ & $3.000,00$ \\
\hline
\end{tabular}

\section{Detalhamento:}

- Aparelhagem de som: 2 microfones, 2 caixas amplificadas 


\section{Musicando}

- Teclado Musical: 1, da marca Yamaha

- Bandinha Musical Infantil - composta de 30 instrumentos de percussão

- Flauta - 200 flautas doce germânicas Yamaha para o primeiro ano, usadas em sistema de rodízio. Para o segundo ano mais 100 flautas, esperando atingir a meta de mais $50 \%$ de alunos matriculados.

- Estantes para partituras: 20 estantes usadas individualmente (número estimado por turma)

- Obras e Infraestrutura - As obras de forração acústica da sala serão realizadas no mês de janeiro, no período de férias escolares.

\section{Despesas correntes}

\begin{tabular}{|c|c|c|}
\hline Material de Consumo & Total Ano 1 & Total Ano 2 \\
\hline Papel Ofício A4 & $2.880,00$ & $3.024,00$ \\
\hline Materias didáticos & $4.180,00$ & $4.400,00$ \\
\hline Total de Despesas & $7.060,00$ & $7.424,00$ \\
\hline
\end{tabular}

\section{Detalhamento:}

- Papel Ofício A4 - 2 pacotes / mês (R\$ 120,00 cada)

- Materiais didáticos: cartucho para impressora, lápis, borracha, lápis de cor

\section{Despesas administrativas e de pessoal}

\begin{tabular}{|c|c|c|}
\hline \multicolumn{2}{|c|}{ Projeção das Despesa Administrativas e de Pessoal } \\
\hline Administrativas & Total Ano 1 & Total Ano 2 \\
\hline Luz Elétrica & $2.400,00$ & $2.448,00$ \\
\hline Marketing & 400,00 & 500,00 \\
\hline Total & $2.800,00$ & $2.948,00$ \\
\hline Pessoal & Total Ano 1 & Total Ano 2 \\
\hline Professores & $18.000,00$ & $18.900,00$ \\
\hline Total & $18.000,00$ & $18.900,00$ \\
\hline Total das Despesas Adm./Pess. & $20.800,00$ & $21.848,00$ \\
\hline
\end{tabular}

\section{Detalhamento:}

- 1 professor - 10 horas/aula por semana 
Necessidade de recursos

\begin{tabular}{|l|c|c|c|}
\hline \multicolumn{4}{|c|}{ Cálculo da Necessidade de Recursos } \\
\hline \multicolumn{1}{|c|}{ Item } & ANO 1 & ANO 2 & TOTAL \\
\hline I. Total das Despesas Correntes & $7.060,00$ & $7.424,00$ & $14.484,00$ \\
\hline Material de Consumo & $7.060,00$ & $7.424,00$ & $14.484,00$ \\
\hline Passagens e Despesas com Locomoção & 0,00 & 0,00 & 0,00 \\
\hline Serviços de Terceiros & 0,00 & 0,00 & 0,00 \\
\hline II. Total de Despesas Administrativas & $2.800,00$ & $2.948,00$ & $5.748,00$ \\
\hline III. Total de Despesas com Pessoal & $18.000,00$ & $18.900,00$ & $36.900,00$ \\
\hline IV. Total de Despesas de Capital (investimentos) & $18.750,00$ & $3.000,00$ & $21.750,00$ \\
\hline Necessidade de Recursos (I+II+III+IV) & $46.610,00$ & $32.272,00$ & $78.882,00$ \\
\hline Recursos Edital & $25.810,00$ & $10.424,00$ & $36.234,00$ \\
\hline Recursos da Organização (contrapartida) & $20.800,00$ & $21.848,00$ & $42.648,00$ \\
\hline
\end{tabular}

